\title{
Avaliação da dureza de dois compósitos restauradores em função da variação da distância da fonte de luz polimerizadora, de uma polimerização adicional e do acabamento superficial ${ }^{1}$
}

\author{
Susana Werner Samuel* \\ Angelo Stefano Secco** \\ Joāo Felipe Mota Pacheco** \\ Léo Werner Süffert*
}

\begin{abstract}
RESUMO
O objetivo deste trabalho foi avaliar a dureza de dois compósitos fotoativados. Os resultados mostraram que a dureza dos materiais variou com o tipo de material, a distância da fonte de luz, a polimerização adicional (60s) e o acabamento superficial.
\end{abstract}

\section{SUMMARY}

Surface hardness studies have been performed on two visible light-activated composit resins. It was found that the surface hardness of these materials varied with: the material, the distance of the light source, the 60 second additional exposure end the surface finish.

\section{UNITERMOS}

Compósitos, Fotopolimerizaçāo, Dureza

\section{Introdução}

O surgimento dos compósitos odontológicos tem provocado uma verdadeira revolução no âmbito da Odontologia Restauradora. A melhora progressiva de suas propriedades físicas tem aumentado rapidamente a sua popularidade (12). O aperfeiçoamento no tamanho, forma e tratamento superficial das partículas de carga dos compósitos tem melhorado o desempenho desses materiais restauradores $(1,5,8,19)$, da mesma forma que a utilização de componentes orgânicos com menor contraçăo de polimerização tem lhes trazido grandes vantagens $(2,7,17,18)$.

Há cerca de dez anos foram introduzidos os compósitos polimerizáveis pela luz visível $(9,19)$ que se apresentam sob a forma de uma pasta única que contém os componentes do sistema iniciador. Quando a luz incide sobre o material, se produzem radicais livres, os quais iniciam a polimerização.

Uma grande vantagem dos materiais fotopolimerizáveis é o longo tempo disponivel para a manipulação e a relativa rapidez de polimerização quando ativados. Algumas das desvantagens são associadas com a polimerização incompleta abaixo da superfície e a taxa de endurecimento dependente assencialmente da concentração do ativador e da intensidade da fonte de luz (14).

O desempenho clínico satisfatório de um material restaurador é determinado principalmente pela sua adaptação ao preparo cavitário e sua resistência à degradação no meio oral. A degradação é o resultado da combinaçăo de vários efeitos, entre eles o desgaste por abrasão e pelas forças mastigatórias que por sua vez dependem da natureza do material (21), do grau de polimerização do compósito (13) e da intensidade da luz incidente na superfície da restauração (11).

Portanto, considerando que existem situaçōes clínicas em que pode haver uma pequena variação na distância entre a fonte polimerizadora e o material restaurador, nos propomos verificar a influência da distância da fonte de luz polimerizadora e de uma polimerização adicional na dureza superficial de alguns compósitos. Além disso, segundo

\footnotetext{
* Professores de Materiais Dentários UFRGS

** C.D. Interno da disciplina de Materiais Dentários - UFRGS

Projeto CNPQ-Institucional: Realizado no laboratório de Materiais Dentários da FO/UFRGS

1 Referenciado com Menção Honrosa durante o IV Salāo de Iniciaçāo Científica PROPESP-UFRGS/1992.
}

\begin{tabular}{|l|l|l|l|l|l|l|} 
R. Fac. Odontol. & Porto Alegre & V. 33 & N. 2 & p.35-38 & DEZEMBRO & 1992 \\
\hline
\end{tabular}


Von Fraunhofer (21) existe nos compósitos convencionais uma camada superficial de baixa dureza devido, provavelmente, a polimerização incompleta da superfície que permanece em contato com 0 ar. $O$ autor sugere que $0,25 \mathrm{~mm}$ de material deveria ser removido da superfície para alcançar uma região de maior resistência. Levando em consideração estes aspectos, analisamos também a influência do acabamento superficial sobre a dureza dos compósitos estudados.

\section{Materiais e Métodos}

Os corpos de prova foram confeccionados em uma matriz metálica que apresenta uma cavidade cilíndrica com $6 \mathrm{~mm}$ de diâmetro e $2,5 \mathrm{~mm}$ de espessura. Os materiais utilizados foram P50 (3M) e Silux Plus (3M).

Cinco corpos de prova de cada material foram polimerizados com um aparelho STAR LIGHT por 60 segundos (16) nas seguintes distâncias: tocando a superfície $(0 \mathrm{~mm})$, a $5 \mathrm{~mm}$, a $10 \mathrm{~mm}$ e a $15 \mathrm{~mm}$ cada, num total de 20 corpos de prova para cada material utilizado.

A matriz metálica foi adaptada à mesa de um microscópio óptico modificado e o condutor de luz permaneceu fixo a um pedestal de tal forma que a movimentação da matriz em relação a fonte de luz foi medida com auxílio de uma escala milimetrada.

Após a polimerização da resina, protegida com uma tira de poliéster, os corpos de prova foram submetidos a ensaios de dureza Knoop em um N.U. Researsh Microscope na superfície e fundo. Para obtenção do valor de dureza foram feitas cinco medidas em cada corpo de prova. Os corpos de prova sofreram então acabamento com discos Soflex (3M) de granulação fina e superfina. Após a obtenção dos resultados, os corpos de prova foram submetidos a uma nova incidência de luz nas mesmas distâncias por mais 60 segundos e novas medidas de dureza da superfície foram tomadas.

Concluídas as mediçōes de dureza na superfície, foram realizadas mediçōes de dureza do fundo dos corpos de prova.

Os resultados foram submetidos à análise estatística pelos testes de $\mathrm{F} \mathrm{e}$ Tukey.

\section{Resultados}

Os resultados foram apresentados sob a forma de gráficos correspondentes aos valores médios obtidos com os ensaios de dureza Knoop. No gráfico 1 temos a comparaçăo de dureza Knoop entre os compósitos P50 (3M) e Silux Plus $(3 \mathrm{M})$, nas regiōes de superfície e fundo, variando a distância da fonte de luz polimerizadora. Observa-se no gráfico 1 que os valores de dureza Knoop para a região de fundo a 10 e $15 \mathrm{~mm}$ no compósito Silux Plus (3M) e $15 \mathrm{~mm}$ no compósito P50 (3M) não estão representados sob forma de colunas, pois a região de fundo não polimerizou nestas distâncias, não sendo possível realizar o ensaio de dureza.

No gráfico 2 temos a dureza Knoop para o compósito P50, comparando as superfícies sem acabamento, com acabamento e acabamento mais polimerizaçăo adicional, variando a distância da fonte de luz polimerizadora.

No gráfico 3 encontra-se a dureza Knoop para o compósito Silux Plus (3M), comparando a superfície sem acabamento, com acabamento e acabamento mais polimerizaçăo adicional variando a distância da fonte de luz polimerizadora.

Os resultados foram submetidos a análise estatística, através dos testes de $\mathrm{F}$ e Tukey, sendo analisada a influência do acabamento superficial, polimerização adicional e da variação da distância da fonte de luz, na dureza superficial e de fundo dos compósitos.

$\mathrm{Na}$ tabela 1 temos a análise para os resultados com o compósito Silux Plus (3M), quanto ao acabamento de superfície e polimerização adicional.

\section{P50/SILUX PLUS MÉDIAS DE DUREZA SUPERFICIE/FUNDO}

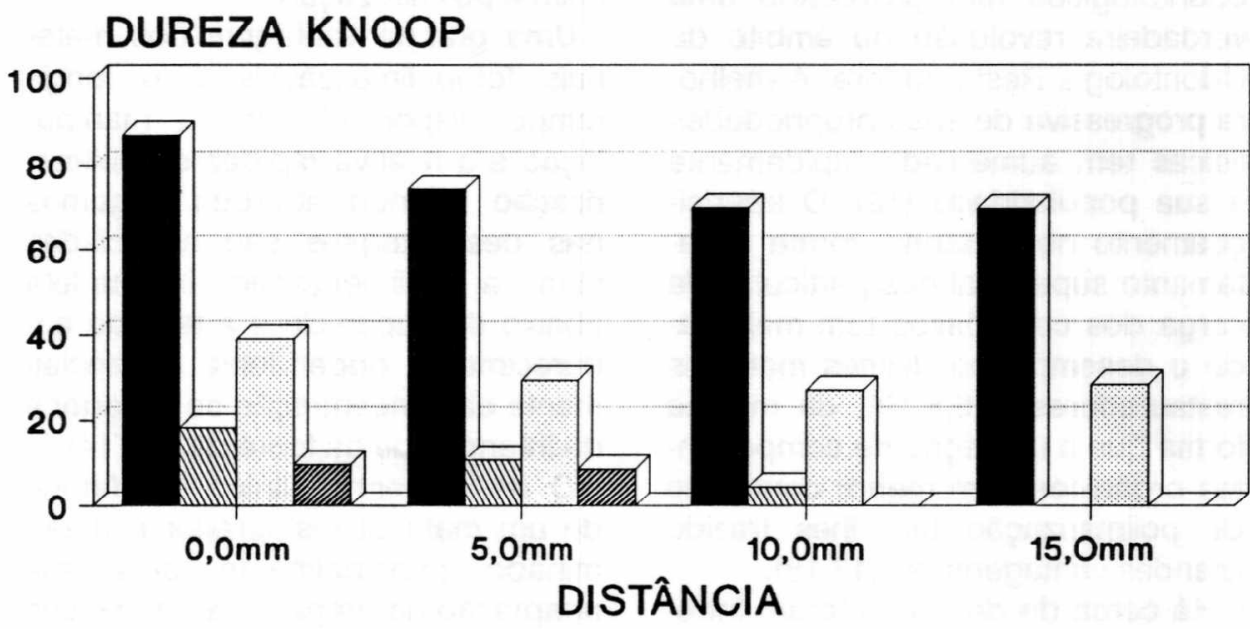

P50 SUPERFICIE

SILUX SUPERFICIE

P50 FUNDO

SILUX FUNDO

GRÁFICO 1: Médias de dureza Knoop da superficie e fundo dos materiais P50 e Silux Plus em função da distância da fonte de luz

R. Fac. Odontol.

Porto Alegre
V. 33

N. 2

p.35-38

DEZEMBRO 
P50 - 3M

MÉDIAS DUREZA PARA TRAT. DE SUPERFICIE

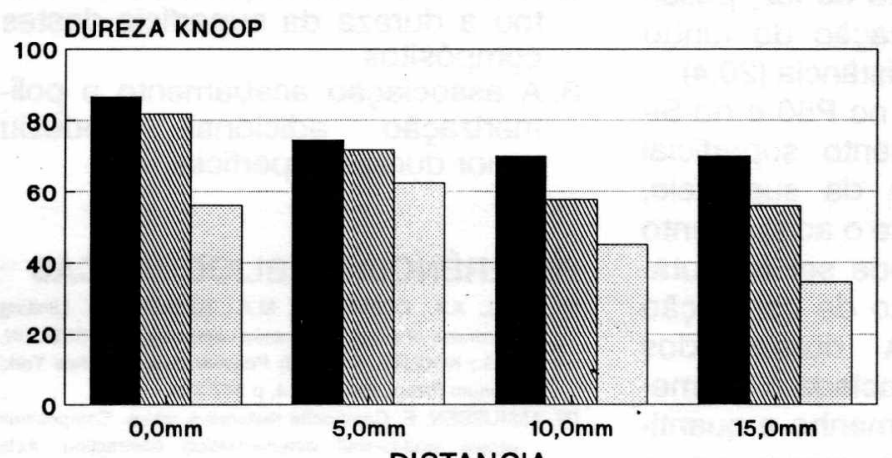

DISTANCIA

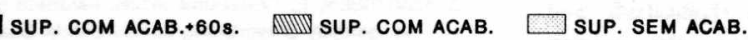

GRÁFICO 2: Médias das durezas Knoop para o P50 (3M), em cada disttancia, quando submetidos aos diversos tratamentos

\section{SILUX PLUS - 3M \\ MÉDIAS DUREZA PARA TRAT. DE SUPERFICIE}

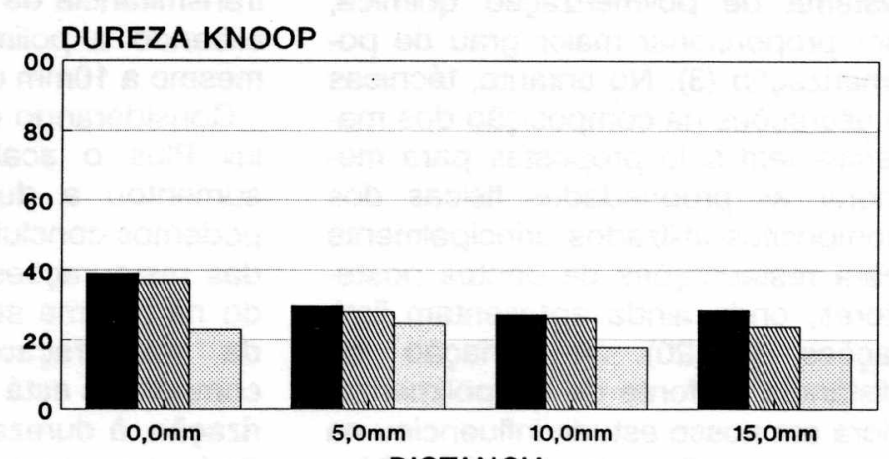

DISTANCIA

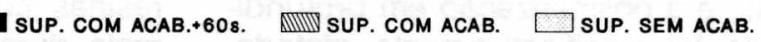

GRÁFICO 3: Módias das durezas Knoop para o Silux Plus (3M), em cada distáncia, quando submetidos aos diversos tratamentos
TABELA 1

Silux Plus: Médias de dureza superficial x tratamento

\begin{tabular}{lccccc}
\hline No $^{\circ}$ rat. & Nome & No Rep. $^{\circ}$ & Médias & $\mathbf{5 \%}$ & $\mathbf{1 \%}$ \\
\hline 3 SILUX & Sup. c/acab. +60s. & 20 & 31,0875 & a & A \\
2 SILUX & Sup. c/acab. & 20 & 28,7800 & b & B \\
1 SILUX & Sup. s/acab. & 20 & 20,3150 & C & C \\
\hline
\end{tabular}

Médias seguidas por letras distintas diferem entre si ao nível de significância indicado D.M.S. $5 \%=1,3788$ - D.M.S. $1 \%=1,7453$

TABELA 2

P50: Médias de dureza superficial x tratamentos

\begin{tabular}{cccccc}
\hline No Trat. & Nome & N $^{\circ}$ Rep. & Médias & $5 \%$ & $1 \%$ \\
\hline 3 P50 & Sup. c/acab. + 60s. & 20 & 74,1935 & a & A \\
2 P50 & Sup. c/acab. & 20 & 66,7125 & b & A \\
1 P50 & Sup. s/acab. & 20 & 49,5940 & C & B \\
\hline
\end{tabular}

Médias seguidas por letras distintas diferem entre si ao nível de significância indicado D.M.S. $5 \%=6,8435$ - D.M.S. $1 \%=8,6624$

TABELA 3

Silux Plus: Médias de dureza superficial x distância

\begin{tabular}{lccccc}
\hline N $^{0}$ Trat. & Nome & No Rep. $^{\circ}$ & Médias & $5 \%$ & $1 \%$ \\
\hline 1 SILUX & $0,0 \mathrm{~mm}$ & 15 & 33,1140 & $\mathrm{a}$ & $\mathrm{A}$ \\
2 SILUX & $5,0 \mathrm{~mm}$ & 15 & 27,3933 & $\mathrm{~b}$ & $\mathrm{~B}$ \\
3 SILUX & $10,0 \mathrm{~mm}$ & 15 & 23,6693 & $\mathrm{C}$ & $\mathrm{C}$ \\
4 SILUX & $15,0 \mathrm{~mm}$ & 15 & 22,7333 & $\mathrm{C}$ & $\mathrm{C}$ \\
\hline
\end{tabular}

Médias seguidas por letras distintas diferem entre si ao nível de significância indicado D.M.S. $5 \%=1,7530$ - D.M.S. $1 \%=2,1669$

TABELA 4

P50: Médias de dureza superficial $x$ distância

\begin{tabular}{cccccc}
\hline No Trat. & Nome & No Rep. $^{\circ}$ & Médias & 5\% & $1 \%$ \\
\hline 1 P50 & $0,0 \mathrm{~mm}$ & 15 & 74,8993 & a & A \\
2 P50 & $5,0 \mathrm{~mm}$ & 15 & 69,5133 & a & A \\
3 P50 & $10,0 \mathrm{~mm}$ & 15 & 56,1426 & b & B \\
4 P50 & $15,0 \mathrm{~mm}$ & 15 & 53,4466 & b & B \\
\hline
\end{tabular}

Médias seguidas por letras distintas diferem entre si ao nível de significância indicado D.M.S. $5 \%=8,7057$ - D.M.S. $1 \%=10,7609$
De acordo com as tabelas 1 e 2 (teste de Tukey), houve diferença estatística significativa ao nível de $5 \%$ de probabilidade para a dureza do compósito Silux Plus e P50 em função dos tratamentos de superfície, ou seja, a superfície com acabamento, obteve dureza estatisticamente superior à superfície sem acabamento. A superfície que sofreu acabamento e 60 segundos de polimerizaçăo adicional apresentou dureza estatisticamente superior à superfície com acabamento.

A influência da distância da fonte de luz polimerizadora na dureza superficial do compósito Silux Plus está representado na tabela 3.

Na tabela 3 podemos obsenvar que para este compósito a distância da fonte de luz interferiu na dureza superficial. E ainda no gráfico 1 observamos que a dureza de fundo foi significativamente alterada com a variação da distância da fonte de luz polimerizadora, pois, para a distância de 10 e $15 \mathrm{~mm}$ o fundo do corpo de prova năo polimerizou, impedindo a realização dos ensaios de dureza.

$\mathrm{Na}$ tabela 4 temos os resultados para o compósito P50 (3M).

De acordo com a tabela 4 , não houve diferença ( $5 \%$ e $1 \%$ ) na dureza superficial do compósito P50 quando a fonte de luz estava a $0 \mathrm{~mm}$ e $5 \mathrm{~mm}$, porém esta dureza mostrou-se estatísticamente inferior quando a distância foi aumentada para $10 \mathrm{~mm}$ e $15 \mathrm{~mm}$.

R. Fac. Odontol.

Porto Alegre

V. 33

N. 2




\section{Discussão}

A ativaçăo pelo sistema de luz visível tem sido preferido em relaçăo ao sistema de polimerização química, por proporcionar maior grau de polimerizaçăo (3). No entanto, técnicas e alterações na composição dos materiais tem sido propostas para meIhorar as propriedades físicas dos compósitos utilizados principalmente para restauraçóes de dentes posteriores, onde ainda apresentam limitações $(4,5,20)$. A variaçăo da distância da fonte de luz polimerizadora em nosso estudo influenciou na dureza superficial do compósito Silux Plus, e a polimerização em profundidade foi significativamente afetada, como podemos obsenvar no gráfico 1. Parece que a 10 e $15 \mathrm{~mm}$ de distância a luz polimerizadora foi incapaz de converter totalmente 0 monômero, em profundidade, resultando uma polimerização incompleta do material. 0 tipo de partícula inorgânica, o índice de refração, 0 tamanho, a forma e quantidade das partículas, deste compósito talvez justifiquem este fenômeno (20). 0 aumento na diferença de dureza entre superfície e fundo, em funçăo da variação da distância, também foi confirmado num estudo de Kanka (10) em 1985. O aumento da distância da fonte de luz ocasiona uma difração dos raios luminosos, prejudicando a polimerização do material.

O grau de dureza superficial dos compósitos Silux Plus e P50 foi diminuído significativamente pelo aumento da distância da fonte de luz, uma vez que a dureza a $0 \mathrm{~mm}$ e $5 \mathrm{~mm}$ foi significativamente maior do que nas distâncias de $10 \mathrm{~mm}$ e $15 \mathrm{~mm}$, para o P50 e a dureza para o Silux foi maior a $0 \mathrm{~mm}$ que a $5 \mathrm{~mm}$ e estas duas maiores que a dureza a $10 \mathrm{~mm}$ e $15 \mathrm{~mm}$ de distância. A dureza de fundo foi igualmente prejudicada com o aumento da distância da fonte de luz, entretanto a diferença observada entre a dureza superficial e de fundo para o P50 foi menor do que a encontrada para o compósito Silux Plus, no qual não houve polimerizaçăo do fundo, já à distância de $10 \mathrm{~mm}$. Talvez as diferentes características da carga inorgânica destes materiais expliquem este fato, já que - maior tamanho das partículas do compósito P50 permite uma maior transmitância da onda de luz, possibilitando a polimerização do fundo mesmo a $10 \mathrm{~mm}$ de distância $(20,4)$.

Considerando que no P50 e no Silux Plus o acabamento superficial aumentou a dureza da superfície, podemos concluir que o acabamento das restaurações pode ser executado na mesma sessão de confecção da restauração. A dureza dos compósitos está associada à polimerização, à dureza, tamanho e quantidade das partículas e geralmente as resinas com partículas maiores são mais duras que aquelas de micropartículas (10). Por isso, talvez, o acabamento que removeu a camada superficial de matriz orgânica mal polimerizada $(13,15)$, expôs maior quantidade de partículas mais duras do P50 promovendo aumento na dureza superficial deste compósito polido, quando comparado com o Silux Plus que apresenta partículas menores e em menor quantidade. Pelo fato de termos encontrado uma grande diferença de dureza da superfície em relação ao fundo e considerando que o monômero residual não polimerizado é extremamente prejudicial em termos mecânicos e de biocompatibilidade (19), sugerimos a técnica incremental como sendo o melhor método para preenchimento de cavidades, observando rigorosamente a espessura das camadas de resina. A dureza superficial diminui com o aumento da distância da fonte de luz polimerizadora e aumenta com uma polimerizaçāo adicional, por isso sempre que se aumentar a distância da fonte de luz devemos aumentar o tempo de exposição, para compensar a difração da luz polimerizadora.

Resumindo, aproximando ao máximo a fonte de luz da superfície do compósito, dando acabamento superficial e acrescentando uma polimerização adicional produzimos meIhores propriedades de dureza nos compósitos testados.

\section{Conclusões}

SILUX PLUS (3M) - P50 (3M)

1. $O$ aumento da distância da fonte de luz polimerizadora diminuiu a dureza superficial e de fundo destes compósitos.

2. $\bigcirc$ acabamento superficial aumentou a dureza da superfície destes compósitos.

3. A associação acabamento e polimerização adicional produziu maior dureza superficial.

\section{REFERÊNCIAS BIBLIOGRÁFICAS}

01. ABELL, A.K.; CRENSHAW, M.A.; TURNER, D.T. Limiting Hardness of polymer/ceramic composites. In: GEBLEIN, G.G.; KOBLTZ, F.F. (Ed) Polymer Science. New York, Plenum Press, 1991. Vol.4, p.347-354.

02. ASMUSSEN, E. Composite restorative resins. Composition versus wall-to-wall polymerization contraction. Acta Odontologica Scandinavica. Oslo, v.33, p.337-344.

03. ASMUSSEN, E. Restorative resins: hardness and strenght vs. quantity of remaining double bonds. Scand. J. Dent. Res., Copenhagen, v.90, n.6, p.484-489, dec. 1982.

04. BLANKENAU, R.J.; KELSEY, W.P.; CAVEL, W.T. ot al. Wavelenght and intensity of seven systems for visible ifght-curing composite resins: a comparison study. J. Am. Dent. Ass. Chicago, v.106, n.4, p.471-474, apr. 1983.

05. BOWEN, R.L. Effects of particle shape and size distribution in a reinforced polymer. J. Am. Dent. Assoc. Chicago, v.69, p. 481-485, 1964.

06. BOWEN, R.L. Compatibility of various materials with oral tissues. I: the componentes in composite restorations. J. Dent. Res., Chicago, v.58, n.5, p.1493-1503, May 1979.

07. CRAIG, R.G. (Ed) Restorative dental materials. Ged. St. Louis: Mosby, 1980. p.186-188.

08. De GEE, A.J.; TEN HARKEL, E.C.; DAVIDSON, C.L. Abrasion of microfilled BIS-GMAVTEGMA resin in relation to its filler content. J. Dent. Res. Washington, DE v.63, p.532 (Abst. $n^{\circ}$ 17), 1984.

09. HANSEN, B.K. Visible light-cured composite resins polymerization contraction pattern and hydroscope expansion. Scand. J. Dent. Res. Copenhagen v.90, p.329-335. 1982.

10. KANCA, J. Visible light-activated composite resins for posterior use - a comparison of surface hardness and uniformity of cure. Update. Quintess. Int. Berlin, v.16, n.10, p.687-690, Oct. 1985.

11. KILIAN, R.J. Visible light cured composite-dependence of cure on light intensity. IADR Program and Abstracts, n.603, 1979.

12. LEINFELDER, K.F. Wear patterns and rates of posterior composite resins. Int. Dent. J. Bristol, v.37, n.3, p.152-157, Sept. 1987.

13. LUNDIN, S.A.; KOCH, G. Cure profiles of visible-light-cured class II composite restorations in vivo and in vitro. Dent. Mater, Washington, DE v.7-8, 1892.

14. Mc LEAN, J.; WILSON, H.J.; BROWN, D. Materiais dentários e suas aplicaçōes. São Paulo: Santos, 1989.

15. ONOSE, H.; SANO, H.; KANTO, H. et al. Selected curing characteristics of light-activated composite resins. Dent. Mater., Washington, DE v.1, n.1, p.48-54, feb. 1985.

16. OTA, K.; KIKUSHI, S.; KOPEL, H.M. et al. Effect of light exposure time on the depht of curing in various composites resin systems. Pediatr. Dent. Chicago, v.7, n.1, p. 19-22, 1983.

17. RUPP, N.W. Clinical placement and performance of composite resin restorations. J. Dent. Res., Washington, v.58, p.1551-1557, 1979.

18. SCHWARTZ, J.L; ANDERSON, M.H.; PELLEU, G.B. Reducing microleakage with the glass-ionomer/resin sandwich technique. Oper. Dent. i, Seattle v.15, p.186-192, 1990.

19. SWARTZ, M.L; PHILUPS, R.W.; RHODES, B.F. Visible Itght-actived resins depht of Cure. J. Am. Dent. Assoc. Chicago, v.106, p.634-637. 1983.

20. TIRTHA, R.; FAN, P.L.; DENNISON, J.B. et al. "In vitro" depht of cure of photo-actived composites. J. Dent. Res. Chicago, v.61, n.10, p.1184-1187, Oct. 1982.

21. VON FRAUNHOFER, J.A. The surface hardness of polymeric restorative materials. Br. Dent. J. London, n.130, p.243-245, Mar. 1971
R. Fac. Odontol.

Porto Alegre

V. 33

N. 2

p.35-38

DEZEMBRO

1992 